\title{
On A Two Dimensional Finsler Space Whose Geodesics Are Semi- Elipses and Pair of Straight Lines
}

\author{
P.K. Srivastava \& V.N.Jha \\ Galgotias College of Engineering \& Technology, Greater Noida
}

\begin{abstract}
It is an interesting problem to find the fundamental function of a two dimensional Finsler space whose geodesics constitute a given family of curves. M. Matsumoto [5],[6],[8] $]^{1)}$ obtained the fundamental function of a two dimensional Finsler space whose geodesics are special conic sections. The aim of the present paper is to obtain the fundamental metric function of two dimensional Finsler space whose geodesics are semielipses and pair of straight lines. We show that such space is locally Minkowskian.
\end{abstract}

\section{Preliminaries.}

Let $\mathrm{F}^{\mathrm{n}}=\left(\mathrm{M}^{\mathrm{n}}, \mathrm{L}(\mathrm{x}, \mathrm{y})\right)$ be an $\mathrm{n}$-dimensional Finsler space on an underlying smooth manifold $\mathrm{M}^{\mathrm{n}}$ with the fundamental function $\mathrm{L}(\mathrm{x}, \mathrm{y})$. The fundamental tensor $\mathrm{g}_{\mathrm{ij}}(\mathrm{x}, \mathrm{y})$, the angular metric tensor $\mathrm{h}_{\mathrm{ij}}(\mathrm{x}, \mathrm{y})$ and the normalized supporting element $\mathrm{l}_{\mathrm{i}}(\mathrm{x}, \mathrm{y})$ are defined respectively by

$\mathrm{g}_{\mathrm{ij}}=\mathrm{h}_{\mathrm{ij}}+\mathrm{l}_{\mathrm{i}} \mathrm{l}_{\mathrm{j}}, \quad \mathrm{h}_{\mathrm{ij}}=\mathrm{LL}_{(\mathrm{i})(\mathrm{j})}, \quad \mathrm{l}_{\mathrm{i}}=\mathrm{L}_{(\mathrm{i})}$

where $\mathrm{L}_{(\mathrm{i})}=\frac{\partial L}{\partial y^{i}}$ and $\mathrm{L}_{(\mathrm{i})(\mathrm{j})}=\frac{\partial^{2} L}{\partial y^{i} \partial y^{j}}$.

The geodesic, the extremal of the length integral $s=\int_{t_{0}}^{t} L(x, y) d t$ where $\mathrm{t} \geq \mathrm{t}_{0}, \quad \mathrm{y}^{\mathrm{i}}=\dot{x}^{i}=\frac{d x^{i}}{d t}$ along an oriented curve $\mathrm{C}: \mathrm{x}^{\mathrm{i}}=\mathrm{x}^{\mathrm{i}}(\mathrm{t})$ from point $\mathrm{P}=\mathrm{x}^{\mathrm{i}}\left(\mathrm{t}_{\mathrm{o}}\right)$ to point $\quad \mathrm{Q}=\mathrm{x}^{\mathrm{i}}(\mathrm{t}), \mathrm{t}>0$, is given by the Euler equation

$$
\frac{d}{d t}\left(\frac{\partial L}{\partial y^{i}}\right)-L_{i}=0
$$

where $L_{i}=\frac{\partial L}{\partial x^{i}}$.

In terms of $\mathrm{F}(\mathrm{x}, \mathrm{y})=\mathrm{L}^{2}(\mathrm{x}, \mathrm{y}) / 2,(1.1)$ is written in the form

$$
\frac{d^{2} x^{i}}{d t^{2}}+2 G^{i}(x, \dot{x})=h(t) \frac{d x^{i}}{d t}
$$

where we put

$$
2 \mathrm{~g}_{\mathrm{ij}} \mathrm{G}^{\mathrm{i}}(\mathrm{x}, \mathrm{y})=\mathrm{y}^{\mathrm{r}}\left(\frac{\partial^{2} F}{\partial x^{r} \partial y J}\right)-\frac{\partial F}{\partial x^{J}}
$$

and $\mathrm{h}(\mathrm{t})=\left(\mathrm{d}^{2} \mathrm{~s} / \mathrm{dt}^{2}\right) /(\mathrm{ds} / \mathrm{dt})$.

Now we consider two dimensional Finsler space and use the notation $(\mathrm{x}, \mathrm{y})$ and $(\mathrm{p}, \mathrm{q})$ respectively, instead of $\left(x^{1}, x^{2}\right)$ and $\left(y^{1}, y^{2}\right)$. The fundamental function $L(x, y ; p, q)$ are positively homogeneous of degree one in $\mathrm{p}$ and $\mathrm{q}$. Therefore, we have
(1.3 a)
$\mathrm{L}_{\mathrm{x}}=\mathrm{pL}_{\mathrm{xp}}+\mathrm{qL} \mathrm{xq}$
$\mathrm{L}_{\mathrm{y}}=\mathrm{pL}_{\mathrm{yp}}+\mathrm{qL} \mathrm{L}_{\mathrm{yq}}$

Also from homogeneity of $\mathrm{L}_{\mathrm{p}}$ and $\mathrm{L}_{\mathrm{q}}$ we have

$$
\frac{L_{p p}}{q^{2}}=\frac{-L_{p q}}{p q}=\frac{L_{q q}}{p^{2}}=W(\text { say }),
$$

where $\mathrm{W}$ is called Weierstrass invariant. Consequently the two equations represented by (1.1) reduce to the single equation

$$
\mathrm{L}_{\mathrm{xq}}-\mathrm{L}_{\mathrm{yp}}+(p \dot{q}-q \dot{p}) W=0,
$$

Keywords: Finsler space, geodesics, locally Minkowskian

2000 Mathematics Subject Classification: 53B40

1) Numbers in square brackets refer to the references at the end of the paper. 
Which is called Weierstrass form of geodesic equation. Now consider the associated fundamental function $\mathrm{A}(\mathrm{x}, \mathrm{y}, \mathrm{z}), \quad \mathrm{z}=\mathrm{y}^{\prime}=\frac{d y}{d x}$ defined as follows:

$$
\mathrm{A}(\mathrm{x}, \mathrm{y}, \mathrm{z})=\mathrm{L}(\mathrm{x}, \mathrm{y} ; 1, \mathrm{z}), \quad \mathrm{L}(\mathrm{x}, \mathrm{y} ; \mathrm{p}, \mathrm{q})=\mathrm{A}\left(\mathrm{x}, \mathrm{y}, \frac{q}{p}\right) \mathrm{p} .
$$

Therefore $\mathrm{L}_{\mathrm{p}}=\mathrm{A}-\mathrm{zA}_{\mathrm{z}}, \quad \mathrm{L}_{\mathrm{q}}=\mathrm{A}_{\mathrm{z}}, \quad \mathrm{L}_{\mathrm{yp}}=\mathrm{A}_{\mathrm{y}}-\mathrm{zA}_{\mathrm{yz}}, \quad \mathrm{L}_{\mathrm{xq}}=\mathrm{A}_{\mathrm{xz}}, \quad \mathrm{L}_{\mathrm{pp}}=\left(\mathrm{z}^{2} / \mathrm{p}\right) \mathrm{Azz}, \quad \mathrm{L}_{\mathrm{pq}}=(-\mathrm{z} / \mathrm{p}) \mathrm{A}_{\mathrm{zz}}, \mathrm{L}_{\mathrm{qq}}=(1 / \mathrm{p})$ $\mathrm{A}_{\mathrm{zz}}$.

On using these values in (1.4), we have

(1.6) $\quad \mathrm{A}_{\mathrm{zz}} \mathrm{y}^{\prime \prime}+\mathrm{A}_{\mathrm{yz}} \mathrm{y}^{\prime}+\mathrm{A}_{\mathrm{xz}}-\mathrm{A}_{\mathrm{y}}=0, \mathrm{z}=\mathrm{y}^{\prime}$,

which is called the Rashevsky form of geodesic equation.

We observe that $\mathrm{y}^{\prime}=\mathrm{q} / \mathrm{p}$ gives $\mathrm{y}^{\prime \prime}=(p \dot{q}-q \dot{p}) / p^{3}$. Hence from (1.2) we have another form of geodesic equation

$$
\mathrm{y}^{\prime \prime}=\frac{2}{p^{3}}\left(q G^{1}-p G^{2}\right) \text {. }
$$

Now in n-dimensional Finsler space $\mathrm{F}^{\mathrm{n}}$ we have the Berwald connection $B \Gamma=\left(G_{j k}^{i}, G_{j}^{i}\right)$; defined by $G_{j}^{i}=\partial G^{i} / \partial y^{j}, G_{j k}^{i}=\partial G_{j}^{i} / \partial y^{k}$ and two kinds of covariant differentiation of Finslerian vector field $V^{i}(\mathrm{x}, \mathrm{y})$ given by

$$
V_{(j)}^{i}=\frac{\partial v^{i}}{\partial x^{j}}-\frac{\partial v^{i}}{\partial y^{r}} G_{J}^{r}+V^{r} G_{r J}^{i}, V_{, j}^{i}=\frac{\partial v^{i}}{\partial y^{j}},
$$

have

Called the $\mathrm{h}$ - and $\mathrm{v}$-covariant derivative of $V^{i}$ respectively. Since $\mathrm{B} \Gamma$ is L-metrical, i.e. $\mathrm{L}_{(\mathrm{i})}=0$, we

$$
L_{i}=l_{r} G_{i}^{r} .
$$

Further from (1.8) we have

$$
L_{i, j}=(1 / L) h_{r j} G_{i}^{r}+l_{r} G_{i j}^{r} .
$$

Next from (1.3) we have $2 \mathrm{~g}_{\mathrm{ij}} \mathrm{G}^{\mathrm{i}} \mathrm{y}^{\mathrm{J}}=\left(\frac{\partial F}{\partial x^{r}}\right) y^{r}$, that is

$$
2 \mathrm{G}^{\mathrm{i}} \mathrm{l}_{\mathrm{i}}=\mathrm{L}^{\mathrm{r}} \mathrm{y}_{\mathrm{r}}
$$

Now we shall return to the two-dimensional case since the matrix $\left(\mathrm{h}_{\mathrm{ij}}\right)$ is of rank one, we get $\varepsilon= \pm 1$ and the vector field $\mathrm{m}_{\mathrm{i}}(\mathrm{x}, \mathrm{y})$ satisfying

(1.11) $\quad \mathrm{h}_{\mathrm{ij}}=\varepsilon \mathrm{m}_{\mathrm{i}} \mathrm{m}_{\mathrm{j}}$,

so we have

(1.12) $\quad g_{i j}=l_{i} 1_{j}+\varepsilon m_{i} m_{j}$

therefore, we get easily

(1.13) $\quad \mathrm{l}_{\mathrm{i}} \mathrm{i}^{\mathrm{i}}=1, \mathrm{l}_{\mathrm{i}} \mathrm{m}^{\mathrm{i}}=\mathrm{m}_{\mathrm{i}} \mathrm{i}^{\mathrm{i}}=0, \mathrm{~m}_{\mathrm{i}} \mathrm{m}^{\mathrm{i}}=\varepsilon$.

Thus we obtain the orthonormal frame field $\left(\mathrm{l}^{\mathrm{i}}, \mathrm{m}^{\mathrm{i}}\right)$, called the Berwald frame. Therefore, we have scalar fields $\mathrm{h}(\mathrm{x}, \mathrm{y} ; \mathrm{p}, \mathrm{q})$ and $\mathrm{k}(\mathrm{x}, \mathrm{y} ; \mathrm{p}, \mathrm{q})$ such that
(1.14) $\left(\mathrm{m}_{1}, \mathrm{~m}_{2}\right)=\mathrm{h}\left(-\mathrm{l}^{2}, \mathrm{l}^{1}\right), \quad\left(\mathrm{m}^{1}, \mathrm{~m}^{2}\right)=\mathrm{k}\left(-\mathrm{l}_{2}, \mathrm{l}_{1}\right), \quad \mathrm{hk}=\varepsilon$.

The equations (1.12) and (1.14) give

$$
\mathrm{g}\left(=\operatorname{det} \mathrm{g}_{\mathrm{ij}}\right)=\mathrm{g}_{11} \mathrm{~g}_{22}-\mathrm{g}_{12}^{2}=\varepsilon\left(\mathrm{l}_{1} \mathrm{~m}_{2}-\mathrm{l}_{2} \mathrm{~m}_{1}\right)^{2}=\varepsilon \mathrm{h}^{2},
$$

and

$$
\frac{1}{h}\left(\mathrm{~m}^{1}, \mathrm{~m}^{2}\right)=\frac{1}{g}\left(-\mathrm{l}_{2}, \mathrm{l}_{1}\right)
$$

We already have $\mathrm{h}_{11}=\mathrm{L} \mathrm{L}_{\mathrm{pp}}=\mathrm{L} \mathrm{Wq}$ and $\mathrm{h}_{11}=\varepsilon\left(\mathrm{m}_{1}\right)^{2}=\varepsilon \mathrm{h}^{2}\left(1^{2}\right)^{2}=\varepsilon \mathrm{h}^{2}\left(\frac{q}{l}\right)^{2}$. Consequently, we have

$$
\mathrm{L}^{3} \mathrm{~W}=\varepsilon \mathrm{h}^{2}=\mathrm{g} .
$$

Now we try to find the expression for $G^{i}$ in the Berwald frame [4] the equations (1.9) and (1.14) give

$\mathrm{L}_{\mathrm{xq}}-\mathrm{L}_{\mathrm{yp}} \quad=\frac{1}{L}\left(h_{r j} G_{i}^{r}-h_{r i} G_{j}^{r}\right)$ 
$=\frac{\varepsilon m_{r}}{L}\left(m_{j} G_{i}^{r}-m_{i} G_{j}^{r}\right)$

$=\frac{\varepsilon m_{r}}{L}\left(m_{2} G_{1}^{r}-m_{1} G_{2}^{r}\right)$

$=\frac{\varepsilon m_{r}}{L} h\left(l^{1} G_{1}^{r}+l^{2} G_{2}^{r}\right)$

$=\frac{\varepsilon m_{r}}{L^{2}} h\left(G_{i}^{r} y^{i}\right)$.

Due to homogeneity of $\mathrm{G}^{\mathrm{r}}$ in $\mathrm{y}^{\mathrm{i}}$, we have $G_{i}^{r} y^{i}=2 G^{r}$, therefore

$2 \mathrm{G}^{\mathrm{i}} \mathrm{m}^{\mathrm{i}}=\left(\mathrm{L}_{\mathrm{xq}}-\mathrm{L}_{\mathrm{yp}}\right) \mathrm{L}^{2} / \varepsilon \mathrm{h}$.

Using $2 G^{i}\left(l_{i} l^{j}+\varepsilon m_{i} m^{j}\right)=\left(L_{r} y^{r}\right) l^{j}+m^{j}\left(L_{x q}-L_{y p}\right) L^{2} / h$ and (1.10) leads to

$2 \mathrm{G}^{\mathrm{i}}=\left(\mathrm{L}_{\mathrm{r}} \mathrm{y}^{\mathrm{r}}\right) \mathrm{1}^{\mathrm{i}}+\left(\mathrm{L}^{2} / \mathrm{h}\right)\left(\mathrm{L}_{\mathrm{xq}}-\mathrm{L}_{\mathrm{yp}}\right) \mathrm{m}^{\mathrm{i}}$

If we put

$\mathrm{L}_{\mathrm{r}} \mathrm{y}^{\mathrm{r}}=\mathrm{L}_{\mathrm{o}}$ and $\mathrm{L}_{\mathrm{xq}}-\mathrm{L}_{\mathrm{yp}}=\mathrm{M}$ in (1.18), and using (1.16) and (1.17) we get

$$
2 \mathrm{G}^{1}=\frac{1}{L}\left(L_{0} p-\frac{M}{W} L_{q}\right), 2 \mathrm{G}^{2}=\frac{1}{L}\left(L_{0} q-\frac{M}{W} L_{p}\right) \text {. }
$$

\section{From geodesics to the Finsler metric.}

Let us consider a family of curves $\{C(a, b)\}$ on the $(x, y)-$ plane $\mathrm{R}^{2}$, given by the equation (2.1) $\quad \mathrm{y}=\mathrm{f}(\mathrm{x}, \mathrm{a}, \mathrm{b})$,

with two parameters (a, b). Differentiating (2.1) with respect to $x$, we get

(2.2)

$$
\mathrm{z}\left(=\mathrm{y}^{\prime}\right)=\mathrm{f}_{\mathrm{x}}(\mathrm{x}, \mathrm{a}, \mathrm{b}) \text {. }
$$

Solving (2.1) and (2.2) for $\mathrm{a}, \mathrm{b}$, we find

(2.3) $\quad \mathrm{a}=\alpha(\mathrm{x}, \mathrm{y}, \mathrm{z}), \mathrm{b}=\beta(\mathrm{x}, \mathrm{y}, \mathrm{z})$.

In view of (2.3) the differentiation of (2.2) leads to

(2.4) $\quad z^{\prime}=f_{x x}(x, a, b)=u(x, y, z)$,

which is precisely the second order differential equation of $y$ characterizing $\{C(a, b)\}$.

Now we are concerned with the Rashevsky form (1.6) of geodesic equation $\quad \mathrm{L}_{\mathrm{qq}}=\mathrm{A}_{\mathrm{zz}} / \mathrm{p}$ and $\mathrm{A}_{\mathrm{zz}}=\mathrm{Wp}^{3}$, hence from (1.5) and (1.17) we have

(2.5) $\quad \mathrm{L}^{3} \mathrm{~W}=\mathrm{A}^{3} \mathrm{~A}_{z z}=\mathrm{g}$.

Thus it is suitable to call $\mathrm{A}_{z z}$ the associated Weierstrass invariant. If we put $\mathrm{B}=\mathrm{A}_{z z}$, then the differentiation of (1.6) with respect to $\mathrm{z}$ gives

(2.6) $\quad \mathrm{B}_{\mathrm{x}}+\mathrm{B}_{\mathrm{y}} \mathrm{z}+\mathrm{B}_{\mathrm{z}} \mathrm{u}+\mathrm{Bu}_{\mathrm{z}}=0$,

which is first order quasilinear partial differential equation. Its auxiliary equations are given by

$$
\frac{d x}{1}=\frac{d y}{z}=\frac{d z}{u}=\frac{d B}{-B u_{z}}
$$

Now defining $\mathrm{U}(\mathrm{x}, \mathrm{a}, \mathrm{b})$ and $\mathrm{V}(\mathrm{x}, \mathrm{y}, \mathrm{z})$ by

we obtain

$$
\mathrm{U}(\mathrm{x} ; \mathrm{a}, \mathrm{b})=\exp \int u_{z}\left(x, f, f_{x}\right) d x, \quad \mathrm{~V}(\mathrm{x}, \mathrm{y}, \mathrm{z})=\mathrm{U}(\mathrm{x} ; \alpha, \beta),
$$

$$
\mathrm{B}(\mathrm{x}, \mathrm{y}, \mathrm{z})=\frac{H(\alpha, \beta)}{V(x, y, z)},
$$

where $\mathrm{H}$ is an arbitrary non-zero function of two arguments.

From $\mathrm{A}_{\mathrm{zz}}=\mathrm{B}$ we get $\mathrm{A}$ in the form

$$
\left\{\begin{array}{c}
A(x, y, z)=A^{*}(x, y, z)+C(x, y)+D(x, y) z, \\
A^{*}=\int\left\{\int B(x, y, z) d z\right\} d z=\int_{z_{0}}^{z}(z-t) \cdot B(x, y, t) d t .
\end{array}\right.
$$

where $\mathrm{C}$ and $\mathrm{D}$ are arbitrary but must be chosen so that A may satisfy (1.6), that is 


$$
\mathrm{C}_{\mathrm{y}}-\mathrm{D}_{\mathrm{x}}=A_{z z}^{*} u+A_{y z}^{*} z+A_{x z}^{*}-A_{y}^{*} .
$$

If a pair $\left(\mathrm{C}_{0}, \mathrm{D}_{0}\right)$ has been chosen so as to satisfy $(2.11)$. Then $\left(\mathrm{C}-\mathrm{C}_{0}\right)_{\mathrm{y}}=\left(\mathrm{D}-\mathrm{D}_{0}\right)_{\mathrm{x}}$, so that we have locally a function $\mathrm{E}(\mathrm{x}, \mathrm{y})$ satisfying $\mathrm{E}_{\mathrm{x}}=\mathrm{C}-\mathrm{C}_{0}$ and $\mathrm{E}_{\mathrm{y}}=\mathrm{D}-\mathrm{D}_{0}$. Thus (2.10) is written as

$\mathrm{A}=\mathrm{A}^{*}+\mathrm{C}_{0}+\mathrm{D}_{0} \mathrm{z}+\mathrm{E}_{\mathrm{x}}+\mathrm{E}_{\mathrm{y}} \mathrm{z}$.

Therefore (1.5) leads to fundamental function

$$
\left\{\begin{array}{c}
L(x, y ; p, q)=L_{0}(x, y ; p, q)+e(x, y, p, q) \\
L_{0}=A^{*}\left(x, y, \frac{q}{p}\right) p+C_{0}(x, y) p+D_{0}(x, y) q
\end{array}\right.
$$

where $\mathrm{e}$ is the derived form given by

$$
e(x, y ; p, q)=E_{x} d x+E_{y} d y \text {. }
$$

Thus, we see that the Finsler metric is uniquely determined when the functions $\mathrm{H}$ and $\mathrm{E}$ of two arguments are chosen. Further, for different choice of the function $\mathrm{H}$ we obtain Finsler spaces which are projective to each other because each one has the same geodesics $\{C(a, b)\}$.

\section{Family of semi-elipses.}

Let us consider the family of semi-elipses $\{\mathrm{C}(\mathrm{a}, \mathrm{b})\}$ given by the equation$$
\mathrm{x}^{2}+\mathrm{ay} \mathrm{y}^{2}=\mathrm{b}, \quad \mathrm{y}, \mathrm{b}>0,
$$

on the semiplane $R_{+}^{2}$

From (3.1) we have

$$
\text { (3.2) } \quad 2 x+2 a y z=0, \quad z=y^{\prime} \text {. }
$$

Consequently the functions $\alpha(\mathrm{x}, \mathrm{y}, \mathrm{z}), \beta(\mathrm{x}, \mathrm{y}, \mathrm{z})$ and $\mathrm{u}(\mathrm{x}, \mathrm{y}, \mathrm{z})$ of the preceding sections are given by

$$
\begin{aligned}
& a=-\frac{x}{y z}=\alpha(x, y, z), b=x^{2}-\frac{x y}{z}=\beta(x, y, z), \\
& z^{\prime}=\frac{z}{x}-\frac{z^{2}}{y}=u(x, y, z) .
\end{aligned}
$$

From (3.4) we get

$$
y^{\prime \prime}=\frac{y^{\prime}}{x}-\frac{\left(y^{\prime}\right)^{2}}{y},
$$

which characterizes the family $\{\mathrm{C}(\mathrm{a}, \mathrm{b})\}$.

Now we find the function $\mathrm{U}(\mathrm{x} ; \mathrm{a}, \mathrm{b})$ and $\mathrm{V}(\mathrm{x} ; \mathrm{y}, \mathrm{z})$ defined by (2.8). Differentiating (3.4) we get

$u_{z}=\frac{1}{x}-\frac{2 z}{y}=\frac{1}{x}-\frac{2 x}{x^{2}-b} \quad$ and

$\mathrm{U}(\mathrm{x} ; \mathrm{a}, \mathrm{b})=\exp \int\left(\frac{1}{x}-\frac{2 x}{x^{2}-b}\right) d x=\frac{x}{x^{2}-b}, \quad V(x, y, z)=\frac{z}{y}$.

Thus, (2.9) implies that

$\mathrm{B}(\mathrm{x}, \mathrm{y}, \mathrm{z})=\mathrm{H}(\alpha, \beta) \frac{y}{z}=-\frac{y^{2}}{x} \alpha \mathrm{H}(\alpha, \beta)$.

On account of the arbitrariness of $\mathrm{H}$, we may write $\mathrm{B}$ as $\mathrm{B}=\mathrm{H}(\alpha, \beta) \frac{y^{2}}{x}$ and $\mathrm{A}^{*}$ of $(2.10)$ is written in the form

$$
\mathrm{A}^{*}(\mathrm{x}, \mathrm{y}, \mathrm{z})=\frac{y^{2}}{x} \iint H(\alpha, \beta)(d z)^{2},
$$

or

$$
\mathrm{A}^{*}(\mathrm{x}, \mathrm{y}, \mathrm{z})=\frac{y^{2}}{x} \int_{1}^{z}(z-t) F(t) d t, \quad F(t)=H\left(-\frac{x}{y t}, x^{2}-\frac{x y}{t}\right) .
$$

We have taken the limit of integration from 1 to $\mathrm{z}$ instead of 0 to $\mathrm{z}$ because $\mathrm{t}$ is in the denominator of $\mathrm{F}(\mathrm{t})$. 
Now if we put $\mathrm{F}_{1}(\mathrm{t})=\mathrm{H}_{\alpha}\left(-\frac{x}{y t}, x^{2}-\frac{x y}{t}\right), \quad \mathrm{F}_{2}(\mathrm{t})=\mathrm{H}_{\beta}\left(-\frac{x}{y t}, x^{2}-\frac{x y}{t}\right)$,

then from (2.10) and (2.11) we have

$$
\begin{aligned}
& \text { (3.7) } \mathrm{C}_{\mathrm{y}}-\mathrm{D}_{\mathrm{x}} \quad=\left(\frac{y^{2} z}{x^{2}}-\frac{y z^{2}}{x}\right) H(\alpha, \beta)-\frac{y^{2}}{x^{2}} \int_{1}^{z} F(t) d t+\int_{1}^{z} F_{1}(t) d t+y^{2} \int_{1}^{z} F_{2}(t) d t \\
& -\frac{y}{x} \int_{1}^{z} \frac{F_{1}(t)}{t} d t-\frac{y^{3}}{x} \int_{1}^{z} \frac{F_{2}(t)}{t} d t+\frac{2 y}{x} \int_{1}^{z} t F(t) d t .
\end{aligned}
$$

Therefore we have:

Theorem 1. Every associated fundamental function $\mathrm{A}(\mathrm{x}, \mathrm{y}, \mathrm{z})$ of a Finsler space $\left(R_{+}^{2}, L(x, y ; p, q)\right)$ having the semi-elipses (3.1) as the geodesics is given by $\mathrm{A}(\mathrm{x}, \mathrm{y}, \mathrm{z})=\mathrm{A}^{*}(\mathrm{x}, \mathrm{y}, \mathrm{z})+\mathrm{C}(\mathrm{x}, \mathrm{y})+\mathrm{D}(\mathrm{x}, \mathrm{y}) \mathrm{z}$,

where $\mathrm{A}^{*}$ is defined by $(3.6)^{\prime}, \mathrm{H}$ is an arbitrary function of $(\alpha, \beta)$ given by $(3.3)$ and the function $(\mathrm{C}, \mathrm{D})$ must be chosen so as to satisfy (3.7).

Example. In particular, we first put $\mathrm{H}(\alpha, \beta)=(\alpha)^{\mathrm{n}}$ for a real number $\mathrm{n}$. Then $\mathrm{F}(\mathrm{t})=\left(-\frac{x}{y t}\right)^{n}$, hence from (3.6)' and (3.7) we have

$$
A^{*}=\frac{y^{2}}{x} \int_{1}^{z}(z-t)\left(-\frac{x}{y t}\right)^{n} d t
$$

or

$$
\mathrm{A}^{*}=\frac{(-1)^{n} x^{n-1}}{(1-n)(2-n) y^{n-2}}\left[z^{2-n}-(2-n) z+(1-n)\right]
$$

and

$$
\mathrm{C}_{\mathrm{y}}-\mathrm{D}_{\mathrm{x}}=(-1)^{n}\left[\frac{x^{n-2}}{y^{n-2}}-\frac{x^{n-1}}{y^{n-1}}\right] \text {. }
$$

If we choose $\mathrm{C}=-\frac{(-1)^{n} x^{n-1}}{y^{n-2}(2-n)}$ and $\mathrm{D}=\frac{(-1)^{n} x^{n-1}}{y^{n-2}(1-n)}$, we have

$$
\mathrm{A}(\mathrm{x}, \mathrm{y}, \mathrm{z})=\frac{(-1)^{n} x^{n-1} z^{2-n}}{(1-n)(2-n) y^{n-2}} \text {. }
$$

Therefore it follows from (1.5) that, the fundamental function

$$
L(x, y ; p, q)=x^{n-1} y^{2-n} p^{n-1} q^{2-n}, n \neq 1,2
$$

where $\frac{(-1)^{n}}{(1-n)(2-n)}$ was omitted.

Case I. If $\mathrm{n}=1$, then (3.8) and (3.9) gives

$\mathrm{A}^{*}=-y(\mathrm{z} \log |\mathrm{z}|-\mathrm{z}+1), \quad \mathrm{C}_{\mathrm{y}}-\mathrm{D}_{\mathrm{x}}=-\frac{y}{x}-1$.

Choosing $\mathrm{C}=\frac{-y^{2}}{2 x}, \mathrm{D}=\mathrm{x}$ we have $\mathrm{A}(\mathrm{x}, \mathrm{y}, \mathrm{z})=z(y-y \log |z|+x)-y-\frac{y^{2}}{2 x}$,

Consequently, we obtain fundamental function 


$$
\mathrm{L}(\mathrm{x}, \mathrm{y} \cdot \mathrm{p}, \mathrm{q})=q\left(y-y \log \left|\frac{q}{p}\right|+x\right)+y p-\frac{y^{2} p}{2 x} .
$$

Therefore, $\mathrm{L}_{\mathrm{xq}}=1, \mathrm{~L}_{\mathrm{yp}}=\frac{q}{p}-\frac{y}{x}+1, L_{p p}=\frac{-q y}{p^{2}}$. From (1.3b) we have $W=\frac{-y}{q p^{2}}$, so using these values in (1.4), where we use $(p \dot{q}-q \dot{p})=y^{\prime \prime} p^{3}$ and $\frac{q}{p}=z=y^{\prime}$. Then it leads to (3.5) immediately.

Case II. If $\mathrm{n}=2$, we have similarly $\mathrm{A}^{*}=x(z-\log |z|-1), \mathrm{C}_{\mathrm{y}}-\mathrm{D}_{\mathrm{x}}=-\frac{x}{y}+1$.

Choosing $\mathrm{C}=\mathrm{y}$ and $\mathrm{D}=\frac{x^{2}}{2 y}$, we have $\mathrm{A}(\mathrm{x}, \mathrm{y}, \mathrm{z})=x\left(z-1-\log |z|+\frac{x z}{2 y}\right)+y$. Therefore, we obtain the metric

$$
\mathrm{L}(\mathrm{x}, \mathrm{y} ; \mathrm{p}, \mathrm{q})=\mathrm{qx}-\mathrm{px}-\mathrm{xp} \log \left|\frac{q}{p}\right|+\frac{x^{2} q}{2 y}+y p .
$$

Now we shall return to the general case with the Finsler metric (3.11). If we refer to the new co-ordinate system $(\bar{x}, \bar{y})=\left(\frac{x^{2}}{2}, \frac{y^{2}}{2}\right)$, then we have $(\mathrm{p}, \mathrm{q})=\left(\frac{\bar{p}}{\sqrt{2 \bar{x}}}, \frac{\bar{q}}{\sqrt{2 \bar{y}}}\right)$ and the metric (3.11) can be written in the form

$$
\bar{L}\left(\bar{x}, \bar{y} ; \bar{p}, \bar{q}=(-1)^{n}(\bar{q})^{2-n}(\bar{p})^{n-1}\right. \text {. }
$$

Since $\bar{L}$ does not depend on $\bar{x}$ and $\bar{y}$, this is a simple metric, called a locally Minkowskian metric and $(\bar{x}, \bar{y})$ is an adapted co-ordinate system to the structure. Further its main scalar I is constant. Since (3.11)' is of the form (i) or (iv) of Theorem 3.5.3.2 of [1], we have directly as follows:

(i) $\varepsilon=1, \mathrm{I}^{2}>4, \quad(2-\mathrm{n})(\mathrm{n}-1)<0, \frac{I}{\sqrt{I^{2}-4}}+1=2(2-\mathrm{n})$,

(ii) $\varepsilon=-1, \quad(2-\mathrm{n})(\mathrm{n}-1)>0, \quad \frac{I}{\sqrt{I^{2}+4}}+1=2(2-\mathrm{n})$.

Therefore we have:

Proposition 1. The Finsler space $\left(R_{+}^{2}, L(x, y, p, q)\right)$ with a metric (3.11) is locally Minkowskian and has the signature $\varepsilon$ and the constant main scalar I as follows:

$$
\begin{aligned}
& n<1, \quad>2: \varepsilon=1, \mathrm{I}^{2}=\frac{(2 n-3)^{2}}{(n-2)(n-1)}, \\
& 1<n<2: \varepsilon=-1, \mathrm{I}^{2}=-\frac{(2 n-3)^{2}}{(n-2)(n-1)} .
\end{aligned}
$$

Remark. $\frac{(2 n-3)^{2}}{(n-2)(n-1)}=4+\frac{1}{n-2}-\frac{1}{n-1}$. The graph of $\mathrm{I}^{2}$ is shown in figure.

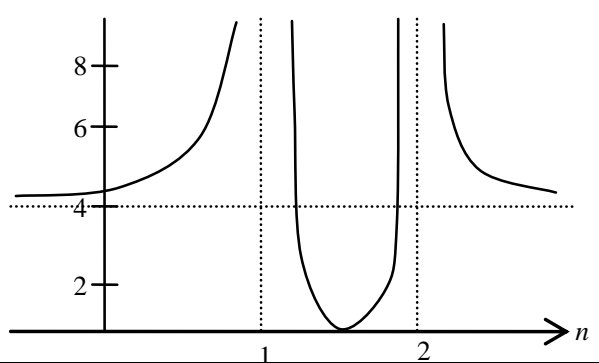


Since a Finsler space of dimension two is Riemannian if and only if $\mathrm{I}=0$. Therefore, The Finsler space $\left(R_{+}^{2}, L(x, y, p, q)\right)$ under consideration is Riemannian if and only if $\mathrm{n}=3 / 2$.

\section{Family of pair of straight lines.}

Let us consider the family of pair of straight lines $\{C(a, b)\}$ given by the equation

(4.1) $\quad(x-a)^{2}-b^{2}=0, \quad y, \quad b>0$,

on the semiplane $R_{+}^{2}$.

From (4.1) we have

(4.2) $\quad 2(x-a)=2 b y z=0, \quad z=y^{\prime}$.

Consequently the functions $\alpha(\mathrm{x}, \mathrm{y}, \mathrm{z}), \beta(\mathrm{x}, \mathrm{y}, \mathrm{z})$ and $\mathrm{u}(\mathrm{x}, \mathrm{y}, \mathrm{z})$ of the preceding sections are given by

$$
\begin{aligned}
& a=x-\frac{y}{z}=\alpha(x, y, z), b=\frac{1}{z^{2}}=\beta(x, y, z), \\
& z^{\prime}=0=u(x, y, z) .
\end{aligned}
$$

From (4.4) we get

$$
y^{\prime \prime}=0 \text {, }
$$

which characterizes the family $\{C(a, b)\}$.

Now we find the function $\mathrm{U}(\mathrm{x} ; \mathrm{a}, \mathrm{b})$ and $\mathrm{V}(\mathrm{x} ; \mathrm{y}, \mathrm{z})$ defined by (2.8). Differentiating (4.4) we get

$$
u_{z}=0 \text { and } \mathrm{U}(\mathrm{x} ; \mathrm{a}, \mathrm{b})=\exp \int 0 d x=1, \quad V(x, y, z)=1 \text {. }
$$

Thus, (2.9) implies that $\mathrm{B}(\mathrm{x}, \mathrm{y}, \mathrm{z})=\mathrm{H}(\alpha, \beta)$.

Therefore, $\mathrm{A}^{*}$ of (2.10) is written in the form

or

$$
\mathrm{A}^{*}(\mathrm{x}, \mathrm{y}, \mathrm{z})=\iint H(\alpha, \beta)(d z)^{2},
$$

$$
\mathrm{A}^{*}(\mathrm{x}, \mathrm{y}, \mathrm{z})=\int_{1}^{z}(z-t) F(t) d t, \quad F(t)=H\left(x-\frac{y}{t}, \frac{1}{t^{2}}\right) .
$$

We have taken the limit of integration from 1 to $\mathrm{z}$ instead of 0 to $\mathrm{z}$ because $\mathrm{t}$ is in the denominator of $\mathrm{F}(\mathrm{t})$.

Now if we put $\mathrm{F}_{1}(\mathrm{t})=\mathrm{H}_{\alpha}\left(x-\frac{y}{t}, \frac{1}{t^{2}}\right), \quad \mathrm{F}_{2}(\mathrm{t})=\mathrm{H}_{\beta}\left(x-\frac{y}{t}, \frac{1}{t^{2}}\right)$, then from (2.10) and (2.11) we have

$$
\mathrm{C}_{\mathrm{y}}-\mathrm{D}_{\mathrm{x}}=\int_{1}^{z} F_{1}(t) d t-\int_{1}^{z} F_{2}(t) d t
$$

Therefore we have:

Theorem 1. Every associated fundamental function $\mathrm{A}(\mathrm{x}, \mathrm{y}, \mathrm{z})$ of a Finsler space $\left(R_{+}^{2}, L(x, y ; p, q)\right)$ having the pair of straight lines (4.1) as the geodesics is given by

$\mathrm{A}(\mathrm{x}, \mathrm{y}, \mathrm{z})=\mathrm{A}^{*}(\mathrm{x}, \mathrm{y}, \mathrm{z})+\mathrm{C}(\mathrm{x}, \mathrm{y})+\mathrm{D}(\mathrm{x}, \mathrm{y}) \mathrm{z}$,

where $\mathrm{A}^{*}$ is defined by $(4.6)^{\prime}, \mathrm{H}$ is an arbitrary function of $(\alpha, \beta)$ given by (4.3) and the function $(\mathrm{C}, \mathrm{D})$ must be chosen so as to satisfy (4.7).

Example. In particular, we first put $\mathrm{H}(\alpha, \beta)=(\beta)^{\mathrm{n}}$ for a real number $\mathrm{n}$. Then $\mathrm{F}(\mathrm{t})=\left(\frac{1}{t^{2}}\right)^{n}$, hence from $(4.6)^{\prime}$ and (4.7) we have

$$
A^{*}=\int_{1}^{z}(z-t)\left(\frac{1}{t^{2}}\right)^{n} d t
$$

or

and

$$
\mathrm{A}^{*}=\frac{1}{(1-2 n)(2-2 n)}\left[z^{2-2 n}-(2-2 n) z+(1-2 n)\right]
$$

$$
\mathrm{C}_{\mathrm{y}}-\mathrm{D}_{\mathrm{x}}=0
$$


If we choose $\mathrm{C}=-\frac{1}{(2-2 n)}$ and $\mathrm{D}=\frac{1}{(1-2 n)}$, we have

$$
\mathrm{A}(\mathrm{x}, \mathrm{y}, \mathrm{z})=\frac{z^{2-2 n}}{(1-2 n)(2-2 n)} \text {. }
$$

Therefore it follows from (1.5) that the fundamental function (4.11) $\quad \mathrm{L}(\mathrm{x}, \mathrm{y} ; \mathrm{p}, \mathrm{q})=\mathrm{p}^{2 \mathrm{n}-1} \mathrm{q}^{2-2 \mathrm{n}}, \mathrm{n} \neq 1 / 2,1$,

where $\frac{1}{(1-2 n)(2-2 n)}$ was omitted.

Case I. If $\mathrm{n}=1 / 2$, then (4.8) and (4.9) gives

$\mathrm{A}^{*}=(\mathrm{z} \log |\mathrm{z}|-\mathrm{z}+1), \quad \mathrm{C}_{\mathrm{y}}-\mathrm{D}_{\mathrm{x}}=0$.

Choosing $\mathrm{D}=-\mathrm{C}=1$, we have $\mathrm{A}(\mathrm{x}, \mathrm{y}, \mathrm{z})=z \log |z|$,

Consequently, we obtain fundamental function

$$
\mathrm{L}(\mathrm{x}, \mathrm{y} \cdot \mathrm{p}, \mathrm{q})=q \log \left|\frac{q}{p}\right| .
$$

Therefore, $\mathrm{L}_{\mathrm{xq}}=0, \mathrm{~L}_{\mathrm{yp}}=0, L_{p p}=\frac{q}{p^{2}}$. From (1.3 b) we have $W=\frac{1}{q p^{2}}$, so using these values in (1.4), where we use $(p \dot{q}-q \dot{p})=y^{\prime \prime} p^{3}$ and $\frac{q}{p}=z=y^{\prime}$. Then it leads to (4.5) immediately.

Case II. If $\mathrm{n}=1$, we have similarly $\mathrm{A}^{*}=(z-\log |z|-1), \mathrm{C}_{\mathrm{y}}-\mathrm{D}_{\mathrm{x}}=0$.

Choosing $\mathrm{C}=-\mathrm{D}=1$, we have $\mathrm{A}(\mathrm{x}, \mathrm{y}, \mathrm{z})=-\log |z|$. Therefore, we obtain the metric

$$
\mathrm{L}(\mathrm{x}, \mathrm{y} ; \mathrm{p}, \mathrm{q})=\mathrm{p} \log \left|\frac{q}{p}\right| \text {. }
$$

Now we shall return to the general case with the Finsler metric (4.11). Since it is of quite similar form to $(3.11)^{\prime}$ we get also the result similar to proposition 1 as follows:

Proposition 2. The Finsler space $\left(R_{+}^{2}, L(x, y, p, q)\right)$ with a metric (3.11) is locally Minkowskian and has the signature $\varepsilon$ and the constant main scalar I as follows:

$$
\begin{aligned}
& n<\frac{1}{2}, \quad>1: \varepsilon=1, \mathrm{I}^{2}=\frac{(4 n-3)^{2}}{2(2 n-1)(n-1)}, \\
& \frac{1}{2}<n<1: \varepsilon=-1, \mathrm{I}^{2}=-\frac{(4 n-3)^{2}}{2(2 n-1)(n-1)} .
\end{aligned}
$$

Remark. $\frac{(4 n-3)^{2}}{2(2 n-1)(n-1)}=4+\frac{1}{2(n-1)}-\frac{1}{2 n-1}$. The graph of $\mathrm{I}^{2}$ is shown in figure.

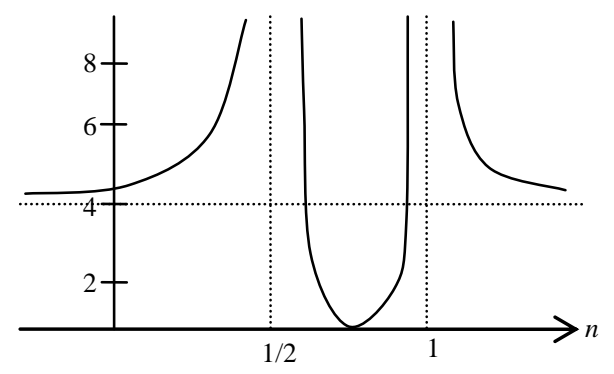

Since a Finsler space of dimension two is Riemannian if and only if $\mathrm{I}=0$. Therefore, The Finsler space $\left(R_{+}^{2}, L(x, y, p, q)\right)$ under consideration is Riemannian if and only if $\mathrm{n}=3 / 4$. 


\section{References}

[1]. P.L. Antonelli, R.S. Ingarden and M. Matsumoto, The Theory of Sprays and Finsler Spaces with Applications in Physics and Biology, Kluwer Acad. Publishers, Dordrecht/Boston/London (1993).

[2]. W. Blaschke, Vorlesungen über Differentialgeometrie I (Dritte Auflage), Springer, 1930 (Chelsea 1967).

[3]. M. Matsumoto, Foundations of Finsler Geometry and Special Finsler Spaces, Kaiseisha Press, Saikawa, Otsu, Japan (1986).

[4]. M. Matsumoto, Projectively flat Finsler spaces of dimension two and an example of projective change, Proc. 5th Natl. Semin. Finsler and Lagrange spaces, Soc. Sti. Mat. Romania, Univ. Brasov, (1988), 233-239.

[5]. M. Matsumoto, The inverse problem of variation calculus in two-dimensional Finsler space, J. Math. Kyoto Univ., 29(1989), 489496

[6]. M. Matsumoto, Geodesics of two-dimensional Finsler spaces, Mathl. Comput. Modelling 20, No. 4/5 (1994), 1-23.

[7]. M. Matsumoto, Every path space of dimension two is projective to a Finsler space, Open systems \& information dynamics, 33(1995), 1-13

[8]. M. Matsumoto, Two-dimensional Finsler spaces whose geodesics constitute a family of special conic sections, J. Math, Kyoto Univ. 35-3(1995), 357-376. 